\title{
Glycopeptide Antibiotic
}

National Cancer Institute

\section{Source}

National Cancer Institute. Glycopeptide Antibiotic. NCI Thesaurus. Code C61101.

One of a class of antibiotics originally isolated from plant and soil bacteria with structures containing either a glycosylated cyclic or polycyclic nonribosomal peptide. These antibiotics inhibit the cell wall structure of susceptible organisms (principally Gram-positive cocci) by inhibiting peptidog lycan synthesis. First-generation glycopeptide antibiotics include vancomycin, teicoplanin, and ramoplanin; second-generation semi-synthetic glycopeptide antibiotics include oritavancin, dalbavancin, and telavancin. 